\title{
The Response of Cerebrospinal Fluid Composition to Sustained Hypercapnia *
}

\author{
Howard L. Bleich, Peter M. Berkman, and William B. Schwartz \\ (From the Department of Medicine, Tufts University School of Medicine, and the Renal \\ Laboratory, Pratt Clinic-New England Center Hospital, Boston, Mass.)
}

That induction of hypercapnia promptly increases the partial pressure of carbon dioxide in the spinal fluid is well recognized (1). The severity of the resulting acidosis depends, therefore, upon the extent to which the concentration of bicarbonate rises. Previous studies of spinal fluid bicarbonate concentration during adaptation to hypercapnia have been so brief that determining if a new steady state was achieved has been impossible (2-4). In addition, most observations have been carried out under unphysiological conditions which complicated interpretation of the experimental results $(2,3)$. There has been, consequently, no satisfactory delineation of the sequential changes in the bicarbonate concentration of the cerebrospinal fluid, nor determination of the relationship between spinal fluid and plasma electrolytes under steady-state conditions.

Our study was undertaken to evaluate the acute and chronic changes in cerebrospinal fluid composition in dogs exposed to $12 \%$ carbon dioxide in an environmental chamber. The data demonstrate that under these conditions there is initially a marked dissociation between the rise in the bicarbonate concentration of plasma water and of spinal fluid, but that a new steady state is ultimately achieved that restores the normal ratios between the cerebrospinal fluid and plasma water concentrations of each electrolyte.

\section{Methods}

Experiments were performed on 35 dogs weighing between 7.7 and $22.7 \mathrm{~kg}$. Each animal was lightly anesthetized with iv thiopental sodium (average dose, $20 \mathrm{mg}$ per $\mathrm{kg}$ ). Promptly thereafter 6 to $12 \mathrm{ml}$ of cerebrospinal fluid was gently aspirated from the cisterna

* Submitted for publication July 18, 1963 ; accepted September 12, 1963.

Supported in part by grants H-759 and HTS 5309 from the National Heart Institute, U. S. Public Health Service, and the Life Insurance Medical Research Fund. magna, and $25 \mathrm{ml}$ of heparinized blood was removed from the femoral artery. Cisternal punctures yielding grossly bloody fluid were immediately repeated; if clear fluid could not be obtained, the dog was discarded.

Five to 8 days after the control specimens were obtained, the dog was placed in a walk-in environmental chamber containing an atmosphere of approximately $12 \%$ carbon dioxide and $21 \%$ oxygen. After various periods of exposure, cerebrospinal fluid and arterial blood were again obtained. Each dog was studied on only one occasion, after a single specified interval in the carbon dioxide atmosphere. The 35 animals were divided into the following 5 groups according to duration of exposure to hypercapnia: 1) one-half hour ( $6 \mathrm{dogs}$ ), 2) 3 hours (6 dogs), 3) 8 hours (6 dogs), 4) 24 hours (10 dogs), and 5) 5 days (7 dogs).

All cisternal punctures were performed with the dogs in the postabsorptive state, usually at least 7 hours after eating. Dogs that did not eat spontaneously during the 5 days of exposure to hypercapnia were tube-fed a nutritionally adequate synthetic diet. Dogs that vomited were discarded.

Cerebrospinal fluid and plasma were analyzed for $\mathrm{pH}$, carbon dioxide content, sodium, potassium, and chloride. Each plasma electrolyte value was expressed as milliequivalents per liter of plasma water, taking the water content of plasma to be $93 \%$ (5). Measurements of plasma water in 8 dogs, by the osmometric method of Albrink, Hald, Man, and Peters (6), were in close agreement with this value (i.e., $\pm 1 \%$ ). $\mathrm{pH}$ was determined at $37^{\circ}$ $\mathrm{C}$ with a blood-parameter analyzer. ${ }^{1}$ Sodium and potassium were determined by flame photometry using the autoanalyzer. ${ }^{2}$ Chloride was determined with a Cotlove chloride titrator, ${ }^{3}$ and total $\mathrm{CO}_{2}$ was measured manometrically.

Mean $\mathrm{pH}$ for each group of data was obtained by converting the individual $\mathrm{pH}$ determinations to hydrogen ion concentrations, averaging these values, and restoring this average to $\mathrm{pH}$ units. Bicarbonate concentration and $\mathrm{PCO}_{2}$ were calculated from the Henderson-Hasselbalch equation, taking the plasma $\mathrm{pK}^{\prime}$ of of carbonic acid to be 6.10 and the solubility factor of carbon dioxide to be 0.0301 . Similar calculations were made for spinal fluid, with a $\mathrm{pK}_{\mathrm{a}}^{\prime}$ of 6.15 and a solubility factor of 0.0324 (7). A comparison was made in 10 dogs between $\mathrm{PCO}_{2}$ values

\footnotetext{
1 Epsco, Inc., Cambridge, Mass.

2 Technicon Instruments, Chauncey, N. Y.

3 American Instrument, Silver Springs, Md.
} 
TABLE I

Acid-base changes induced by 5 days of exposure to $12 \% \mathrm{CO}_{2}{ }^{*}$

\begin{tabular}{|c|c|c|c|c|c|c|c|}
\hline & & $\begin{array}{c}\text { Control } \\
\text { (35 dogs) }\end{array}$ & $\begin{array}{l}\text { One-half hour } \\
\text { (6 dogs) }\end{array}$ & $\begin{array}{l}3 \text { hours } \\
\text { (6 dogs) }\end{array}$ & $\begin{array}{l}8 \text { hours } \\
\text { (6 dogs) }\end{array}$ & $\begin{array}{l}24 \text { hours } \\
(10 \text { dogs })\end{array}$ & $\begin{array}{l}5 \text { days } \\
(7 \text { dogs })\end{array}$ \\
\hline \multirow{2}{*}{$\begin{array}{l}\mathrm{HCO}_{3}^{-} \\
m E q / L\end{array}$} & $\mathrm{CSF} \dagger$ & $23.5 \pm 0.19$ & $25.9 \pm 0.79$ & $31.3 \pm 0.56$ & $34.7 \pm 0.82$ & $35.9 \pm 0.44$ & $35.9 \pm 0.87$ \\
\hline & Plasma water & $\underset{\text { NS }}{24.2 \pm 0.39}$ & $\begin{array}{c}30.8 \pm 1.06 \\
\mathrm{p}<0.001\end{array}$ & $\begin{array}{c}34.3 \pm 1.11 \\
\mathrm{NS}\end{array}$ & $34.3 \underset{\mathrm{NS}}{ \pm} 1.22$ & $\begin{array}{c}32.7 \pm 0.70 \\
\mathrm{p}<0.001\end{array}$ & $37.1 \pm 0.35$ \\
\hline \multirow{2}{*}{$\begin{array}{l}\mathrm{H}^{+}, \\
\quad \text { nmoles } / L \S\end{array}$} & CSF & $44 \pm 0.7$ & $80 \pm 6.1$ & $78 \pm 2.7$ & $65 \pm 2.0$ & $62 \pm 2.2$ & $59 \pm 1.0$ \\
\hline & Plasma & $\begin{array}{c}38 \pm 0.7 \\
\mathrm{p}<0.001\end{array}$ & $\begin{array}{r}67 \pm 3.4 \\
p<0.01\end{array}$ & $65 \underset{\text { NS }}{ \pm 2.7}$ & $63 \underset{\mathrm{NS}}{ \pm}$ & $66 \underset{\mathrm{NS}}{ \pm 2.2}$ & $\begin{array}{c}52 \pm 0.4 \\
\mathrm{p}\end{array}$ \\
\hline \multirow{2}{*}{$\begin{array}{l}\mathrm{pCO}_{2} \\
m m \mathrm{Hg}\end{array}$} & $\mathrm{CSF}$ & $45 \pm 0.7$ & $90 \pm 4.4$ & $106 \pm 3.1$ & \pm 3.8 & \pm 3.1 & $91 \pm 1.4$ \\
\hline & Plasma & $\begin{array}{c}36 \\
\mathrm{p}\end{array} \frac{ \pm 0.9}{0.001}$ & $\begin{array}{r}80 \pm 2.6 \\
p<0.01\end{array}$ & $\begin{array}{c}87 \pm 2.0 \\
p<0.01\end{array}$ & $\begin{array}{c}85 \pm 1.8 \\
p<0.01\end{array}$ & $\begin{array}{c}84 \pm 1.6 \\
p<0.01\end{array}$ & $\begin{array}{c}75 \pm 1.3 \\
\mathrm{p}\end{array}$ \\
\hline
\end{tabular}

* All values are given as the mean $\pm \mathrm{SE}$.

$\dagger \mathrm{CSF}=$ cerebrospinal fluid.

$\ddagger p>0.01$.

$\S \mathrm{nmole}=$ nanomole $\left(10^{-9}\right.$ moles $)$.

obtained for spinal fluid by this calculation and those obtained by direct measurement with the Severinghaus electrode; in each instance the two values agreed closely.

The concentration of carbon dioxide in the chamber was monitored by a Ranarex carbon dioxide analyzer 4 and continuously recorded and automatically regulated to $12 \pm 1 \%$ of the dry gas pressure iv a pneumatic freevane controller. ${ }^{5}$ The concentration of oxygen was intermittently monitored by a Beckman Model $\mathrm{C}$ analyzer,

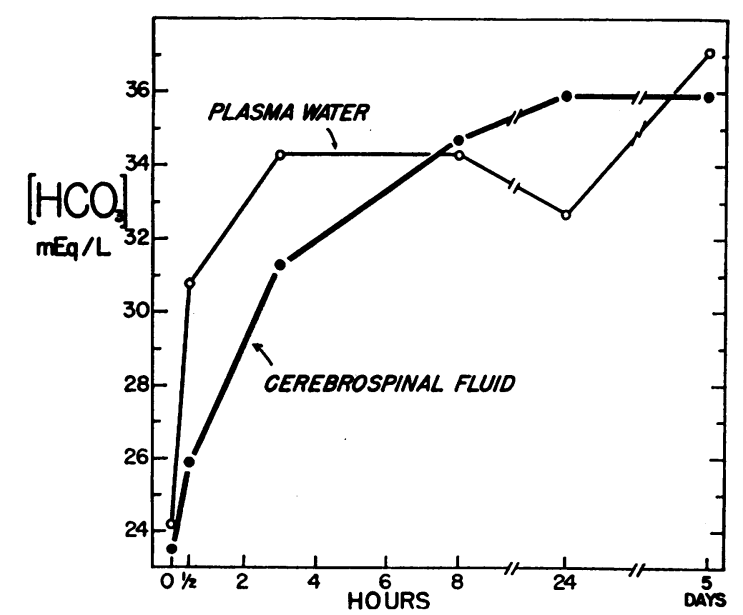

Fig. 1. Relationship betweEn the concentration OF BICARBONATE IN CEREBROSPINAL FLUID AND IN PLASMA WATER DURING EXPOSURE TO $12 \% \mathrm{CO}_{2}$. The control point represents the mean of observations on 35 animals. The experimental points represent the mean of observations on 6 or more dogs (see text). Statistical data are presented in Table $I$.

4 Permutit, New York, N. Y.

5 Bristol Laboratories, New York, N. Y. and the flow of oxygen was manually regulated to maintain a concentration of approximately $21 \%$. Workers, using full face masks with an appropriate air supply, entered and left the chamber via an airlock. With this technique the dogs could be fed, their cages cleaned, and experiments performed without significantly altering the carbon dioxide tension of their environment. The construction and operation of this chamber will be described in detail elsewhere (8).

\section{Results}

Bicarbonate ion. The mean concentrations of bicarbonate for all experiments are presented in Table I and in Figure 1.

a) Cerebrospinal fluid: The mean concentration of bicarbonate after exposure to $12 \%$ carbon dioxide rose progressively from a control value of $23.5 \mathrm{mEq}$ per $\mathrm{L}$ to $34.7 \mathrm{mEq}$ per $\mathrm{L}$ at 8 hours. The value at each point during the first 8 hours was significantly greater than the preceding value. ${ }^{6}$ Between 8 hours and 5 days there was no further significant change.

b) Plasma water: The mean concentration of bicarbonate rose from a control value of 24.2 $\mathrm{mEq}$ per $\mathrm{L}$ to $30.8 \mathrm{mEq}$ per $\mathrm{L}$ at one-half hour $(p<0.001)$. During the remainder of the first day there was no further significant change. The concentration at 5 days $(37.1 \mathrm{mEq}$ per L) was, however, higher than the concentration at 24 hours $(p<0.01)$.

6 A difference between the two means is said to be "significant" when the $t$ yields a value of $\mathrm{p}$ less than 0.01 . 
c) Relationship between cerebrospinal fluid and plasma water: The mean control concentrations of bicarbonate in spinal fluid and in plasma water were not significantly different. After one-half hour of hypercapnia, however, the rise in the concentration of bicarbonate was greater in plasma water than in spinal fluid by $4.2 \mathrm{mEq}$ per $\mathrm{L}(\mathrm{p}<$ $0.01)$. By 8 hours this difference had disappeared, and at 24 hours the relationship was reversed, concentration in spinal fluid exceeding that in plasma water by $3.2 \mathrm{mEq}$ per $\mathrm{L}(\mathrm{p}<$ $0.001)$. At 5 days the concentrations in spinal fluid and plasma water were approximately 13 $\mathrm{mEq}$ per $\mathrm{L}$ higher than were the control values but were not significantly different from each other.

Because the bicarbonate concentration at 24 hours, but at no other time, was significantly higher in cerebrospinal fluid than in plasma water (taking the water content of plasma to be 93\%), 3 additional dogs were studied in the following fashion. Plasma water was determined both by the osmometric method and from plasma protein concentration (6), on both control plasma and on plasma drawn after 24 hours of exposure to hypercapnia. None of these values deviated from the assumed value of $93 \%$ by more than $1 \%$. Plasma bicarbonate was measured after 18, 20, 22 , and 24 hours of exposure to carbon dioxide; all of these values were virtually identical. The bicarbonate concentration in cerebrospinal fluid at 24 hours was in each instance higher than in plasma water (average difference, $3 \mathrm{mEq}$ per $\mathrm{L}$ ). Thus, the finding of a bicarbonate concentration significantly higher in cerebrospinal fluid at 24 hours cannot be attributed either to a decrease in the water content of plasma or to a sudden fall in plasma bicarbonate concentration not yet reflected in cerebrospinal fluid composition.

Carbon dioxide tension and hydrogen ion concentration. The mean concentrations of hydrogen ion and the mean tensions of carbon dioxide for all experiments are shown in Table $\mathrm{I}$ and in Figure 2.

a) Plasma: The mean carbon dioxide tension rose from a control value of $36 \mathrm{~mm} \mathrm{Hg}$ to 80 $\mathrm{mm} \mathrm{Hg}$ after one-half hour of hypercapnia and thereafter varied between 75 and $90 \mathrm{~mm} \mathrm{Hg}$, presumably because of slight fluctuations in the carbon dioxide tension within the chamber.

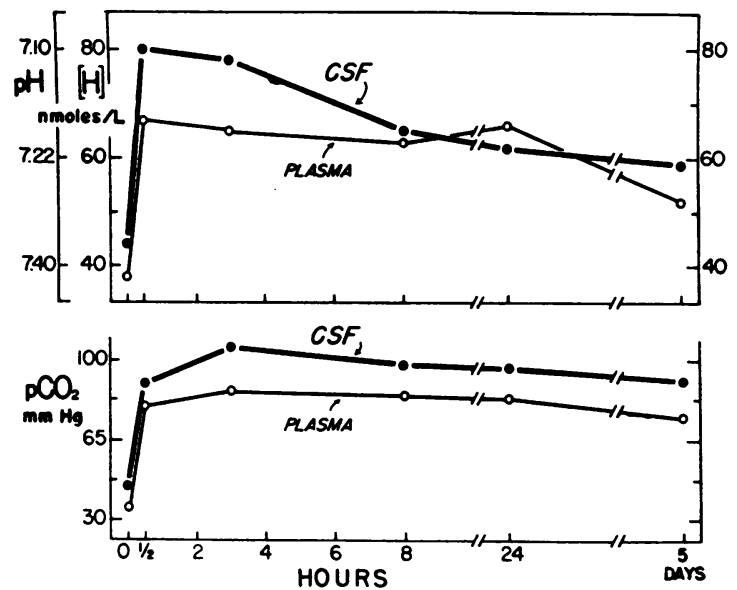

Fig. 2. Plasma and Cerebrospinal Fluid hydrogen ION CONCENTRATIONS AND CARBON DIOXIDE TENSIONS DURING EXPOSURE To $12 \% \mathrm{CO}_{2}$. The control point represents the mean of observations on 35 animals. The experimental points represent the mean of observations on 6 or more animals (see text). Statistical data are presented in Table I.

The mean hydrogen ion concentration in the plasma rose from a control value of 38 nmoles $^{\text {? }}$ per L ( $\mathrm{pH} \mathrm{7.42)}$ to 67 nmoles per L ( $\mathrm{pH} 7.18$ ) after one-half hour of hypercapnia. It remained essentially unchanged during the rest of the first day but at 5 days had decreased to 52 nmoles per $\mathrm{L}(\mathrm{pH} 7.28)$.

b) Cerebrospinal fluid: The mean carbon dioxide tension rose from a control value of $45 \mathrm{~mm}$ $\mathrm{Hg}$ to $90 \mathrm{~mm} \mathrm{Hg}$ after one-half hour of hypercapnia. All subsequent values were approximately $100 \mathrm{~mm} \mathrm{Hg}$.

The mean concentration of hydrogen ion rose from a control value of 44 nmoles per $\mathrm{L}(\mathrm{pH}$ 7.36) to 80 nmoles per L ( $\mathrm{pH} \mathrm{7.10)}$ after one-half hour of hypercapnia. By 8 hours, there was a significant decrease to a mean of 65 nmoles per L. Between 8 hours and 5 days there was no further significant change.

c) Relationships between cerebrospinal fluid and plasma: Before exposure to hypercapnia, the average carbon dioxide tension was approximately $10 \mathrm{~mm} \mathrm{Hg}$ higher in the spinal fluid than in the plasma $(p<0.001)$. Subsequently, the gradient averaged approximately $15 \mathrm{~mm} \mathrm{Hg}$, the carbon dioxide tension in spinal fluid always significantly higher than in plasma.

\footnotetext{
${ }^{7}$ nmole $=$ nanomole $\left(10^{-0}\right.$ moles $)$.
} 
Prior to exposure to hypercapnia, the spinal fluid was significantly more acid than the plasma, the mean hydrogen ion concentration gradient being 6 nmoles per L. After one-half hour of hypercapnia, the hydrogen ion concentration gradient had increased to 13 nmoles per L; but by 24 hours, by virtue of the greater bicarbonate increment in cerebrospinal fluid than in plasma water, there was no longer a significant hydrogen ion gradient between the two compartments. At 5 days, however, as in the control state, the concentration of hydrogen in the spinal fluid again exceeded that in plasma by approximately 7 nmoles per $\mathrm{L}(\mathrm{p}<0.001)$.

Sodium, potassium, and chloride (Table II). The mean control concentrations of sodium and potassium in spinal fluid were $153 \mathrm{mEq}$ per $\mathrm{L}$ and $3.3 \mathrm{mEq}$ per $\mathrm{L}$ and in plasma water were 159 $\mathrm{mEq}$ per $\mathrm{L}$ and $4.4 \mathrm{mEq}$ per L. At 5 days, the concentrations of sodium and potassium in both cerebrospinal fluid and plasma were virtually identical to the concentrations in the controls. Thus, the concentration of sodium in plasma water both before and during chronic hypercapnia exceeded the concentration in spinal fluid by approximately $6 \mathrm{mEq}$ per $\mathrm{L}$. The concentration of potassium in plasma water consistently exceeded that in cerebrospinal fluid by approximately 1.1 $\mathrm{mEq}$ per $\mathrm{L}$.

The mean control concentration of chloride was $130 \mathrm{mEq}$ per $\mathrm{L}$ in the spinal fluid and 119 $\mathrm{mEq}$ per $\mathrm{L}$ in plasma water. Over the 5 days of exposure to hypercapnia the mean concentra-

TABLE II

Electrolyte concentrations after 5 days of exposure to $12 \% \mathrm{CO}_{2}{ }^{*}$

\begin{tabular}{clccc}
\hline \hline & & $\begin{array}{c}\text { Control } \\
(35 \text { dogs })\end{array}$ & $\begin{array}{c}\text { Five days } \\
(7 \text { dogs })\end{array}$ \\
\hline $\begin{array}{c}\mathrm{Na}, \\
m E q / L\end{array}$ & CSF & $153 \pm 0.5$ & $151 \pm 0.7$ \\
& Plasma water & $159 \pm 0.6$ & $156 \pm 0.9$ \\
$\mathrm{~K},{ }_{m E q / L}$ & $\mathrm{CSF}$ & $3.3 \pm 0.04$ & $3.3 \pm 0.12$ \\
& Plasma water & $4.4 \pm 0.06$ & $4.4 \pm 0.11$ \\
$\mathrm{Cl},{ }_{m E q / L}$ & CSF & $130 \pm 0.5$ & $118 \pm 0.9$ \\
& Plasma water & $119 \pm 0.6$ & $105 \pm 0.7$
\end{tabular}

* Each value is given as the mean $\pm \mathrm{SE}$; each of the cerebrospinal fluid concentrations differs from the corresponding plasma water concentrations at a value of $\mathrm{p}<0.001$. tion of chloride decreased to $118 \mathrm{mEq}$ per $\mathrm{L}$ in spinal fluid and to $105 \mathrm{mEq}$ per $\mathrm{L}$ in plasma water. The smallest difference between the concentration of chloride in spinal fluid and in plasma water (3 $\mathrm{mEq}$ per $\mathrm{L}$ ) was observed at 24 hours, the only time at which the concentration of bicarbonate in spinal fluid significantly exceeded that of plasma water.

\section{Discussion}

Studies of changes in cerebrospinal fluid composition during exposure to hypercapnia have been seriously impeded by a variety of technical problems. Chronic studies utilizing a face mask or tracheostomy are impracticable, and acute studies on experimental animals have been feasible only when anesthesia, muscle relaxants, and artificial ventilation are employed $(2,3)$. These latter measures often lead to hypotension or metabolic acidosis, thereby complicating interpretation of the experimental results $(2,3)$.

In the present study these difficulties have been circumvented by placing dogs in an environmental chamber containing an atmosphere of $12 \%$ carbon dioxide. This technique has made possible the production of uninterrupted and prolonged hypercapnia without other alteration of the physiologic state. During the first 24 hours of the dogs' exposure to hypercapnia, the bicarbonate concentration in the spinal fluid rose gradually to a value approximately $13 \mathrm{mEq}$ per $\mathrm{L}$ higher than that in the control state. Subsequently, i.e., between the first and fifth days of exposure, the bicarbonate concentration showed no further significant change. The concentration of bicarbonate in plasma water rose by only $8.5 \mathrm{mEq}$ per $\mathrm{L}$ during the first 24 hours, but after 5 days of exposure it, too, had increased by approximately $13 \mathrm{mEq}$ per L. Thus, when the new steady state had been achieved, ${ }^{8}$ the normal cerebrospinal fluid to plasma ratio of approximately 1.0 had been restored (Table III).

${ }^{8}$ The possibility cannot be excluded that a further slight rise in the concentration of bicarbonate might have occurred with more prolonged exposure. No hint of any such change is provided, however, either by previous studies of plasma composition during 2 weeks of hypercapnia $(9,10)$ or by the present finding of a virtually constant bicarbonate concentration in the cerebrospinal fluid between the first and fifth days of exposure. 
TABLE III

Cerebrospinal fluid to plasma water ratios after 5 days of exposure to $12 \% \mathrm{CO}_{2}$

\begin{tabular}{lccccc}
\hline & $\mathrm{Na}$ & $\mathrm{K}$ & $\mathrm{Cl}$ & $\mathrm{HCO}$ & $\mathrm{H}$ \\
\hline Control & 0.96 & 0.75 & 1.09 & 0.97 & 1.16 \\
Five days & 0.97 & $\mathbf{0 . 7 5}$ & 1.12 & $\mathbf{0 . 9 7}$ & 1.14 \\
\hline
\end{tabular}

These increments in bicarbonate concentration were insufficient to compensate for the increments in the partial pressures of carbon dioxide, the hydrogen ion concentration in each compartment increasing by approximately 15 nmoles per L. The cerebrospinal fluid to plasma ratio for hydrogen, as shown in Table III, was little affected by this change. These findings provide no evidence that the $\mathrm{pH}$ of cerebrospinal fluid is protected during respiratory acidosis in the fashion recently proposed for other acid-base disturbances (11).

The relationship between cerebrospinal fluid and plasma bicarbonate concentrations during the first 24 hours of hypercapnia reveals several additional features of interest. Immediately after the induction of hypercapnia, the rise in the concentration of bicarbonate was much larger in plasma water than in spinal fluid (Figure 1), a finding that could result from slow diffusion of bicarbonate from the plasma. A slow rate of diffusion has, in fact, previously been invoked to explain the stability of spinal fluid bicarbonate concentration during induction of acute metabolic acidosis (1). Clearly, however, the problem is more complex, since diffusion along a concentration gradient cannot account for the finding at 24 hours of a bicarbonate concentration that is significantly higher in cerebrospinal fluid than in plasma water.

The difficulty in explaining these transient changes, as well as the steady-state relationships, stems from the paucity of information concerning the mechanisms normally controlling the distribution of electrolytes between cerebrospinal fluid and plasma. The distribution of ions between the two compartments clearly deviates from the values to be expected if cerebrospinal fluid were in a Donnan equilibrium with plasma. Such a distribution would require the same cerebrospinal fluid to plasma ratio for each of the anions and the reciprocal of this ratio for each of the cations. The finding of different ratios for each ion indicates that even if one ion conforms to a Donnan distribution, the others do not.

On the basis of recent observations that spinal fluid is electropositive to plasma by $3 \mathrm{mv}$ (11, 12), it has been proposed that the asymmetric distribution of chloride (but not of other ions) is a passive consequence of the transmembrane potential (12). The physiologic significance of potential measurements carried out between plasma and cerebrospinal fluid is uncertain, however, especially when the magnitude of such potentials is small. On the other hand, if some transmembrane potential governs the passive distribution of chloride or of any of the measured ions, this potential at 5 days could not have differed from control values by more than $1 \mathrm{mv}$; concentration ratios in the steady state virtually identical to those of the control state would, according to the Nernst equation, require this interpretation.

It is not clear whether this pattern of adaptation to hypercapnia is unique for the dog or whether it is also applicable to man. Manfredi has recently studied three human volunteers in whom $\mathrm{PCO}_{2}$ was elevated to approximately 60 to $70 \mathrm{~mm} \mathrm{Hg}$ for 20 minutes and has observed that the rise in plasma bicarbonate concentration was not reflected in the cerebrospinal fluid (4). The brief period of observation makes the evaluation of this finding difficult. On the other hand, a similar discrepancy has been observed in patients with chronic pulmonary disease, the concentration of bicarbonate in plasma in most instances exceeding that in spinal fluid (13). Whether the plasma bicarbonate concentration in these patients had been stable for a period sufficient to insure a steady-state relationship between the two compartments is unclear. Furthermore, the effects of the associated hypoxia or of a superimposed metabolic acid-base disturbance (14) may have altered a pattern characteristic of a simple hypercapnia. Studies of spinal fluid composition during prolonged hypercapnia in normal man, if these should prove feasible, may serve to clarify this problem.

\section{Summary}

Studies have been carried out in 35 dogs exposed to an atmosphere of $12 \%$ carbon dioxide in an environmental chamber for periods rang- 
ing from one-half hour to 5 days. During the first 24 hours of hypercapnia, the bicarbonate concentration in the spinal fluid gradually rose to a value approximately $13 \mathrm{mEq}$ per $\mathrm{L}$ higher than that of the control state. No further significant change occurred during the subsequent 4-day period of observation. In plasma water the concentration of bicarbonate also rose by approximately $13 \mathrm{mEq}$ per $\mathrm{L}$, but the new steady state was not achieved so quickly as in spinal fluid. The hydrogen ion concentration in both cerebrospinal fluid and plasma was increased by approximately 15 nmoles per L.

After 5 days of hypercapnia, the chloride concentration in both compartments had decreased by an amount nearly identical to the rise in the concentration of bicarbonate. The concentrations of sodium and potassium were not significantly different from the values present in the control state. Despite the changes in the concentrations of bicarbonate, chloride, and hydrogen ion, the cerebrospinal fluid to plasma ratios of all the measured electrolytes in the new steady state were virtually identical to those present in the control state. This finding would suggest, according to the Nernst equation, that if some potential difference governs the partition of any of the measured ions, then this potential at 5 days was virtually identical to that in the control state.

\section{References}

1. Robin, E. D., R. D. Whaley, C. H. Crump, A. G. Bickelmann, and D. M. Travis. Acid-base relations between spinal fluid and arterial blood with special reference to control of ventilation. J. appl. Physiol. 1958, 13, 385.

2. Merwarth, C. R., and H. O. Sieker. Acid-base changes in blood and cerebrospinal fluid during altered ventilation. J. appl. Physiol. 1961, 16, 1016.
3. Swanson, A. G., and H. Rosengren. Cerebrospinal fluid buffering during acute experimental respiratory acidosis. J. appl. Physiol. 1962, 17, 812.

4. Manfredi, F. Acid-base relations between serum and cerebrospinal fluid in man under normal and abnormal conditions. J. Lab. clin. Med. 1962, 59, 128.

5. Dittmer, D. S. Blood and Other Body Fluids. Washington, D. C., Federation of American Societies for Experimental Biology, 1961, p. 19.

6. Albrink, M. J., P. M. Hald, E. B. Man, and J. P. Peters. The displacement of serum water by the lipids of hyperlipemic serum. A new method for the rapid determination of serum water. J. clin. Invest. 1955, 34, 1483.

7. Alexander, S. C., R. Gelfand, and C. J. Lambertsen. The $\mathrm{pK}^{\prime}$ of carbonic acid in cerebrospinal fluid. J. biol. Chem. 1961, 236, 592.

8. Schwartz, W. B., and L. Silverman. To be published.

9. Polak, A., G. D. Haynie, R. M. Hays, and W. B. Schwartz. Effects of chronic hypercapnia on electrolyte and acid-base equilibrium. I. Adaptation. J. clin. Invest. 1961, 40, 1223.

10. Van Ypersele de Strihou, C., P. F. Gulyassy, and W. B. Schwartz. Effects of chronic hypercapnia on electrolyte and acid-base equilibrium. III. Characteristics of the adaptive and recovery process as evaluated by provision of alkali. J. clin. Invest. 1962, 41, 2246.

11. Severinghaus, J. W., and R. A. Mitchell. Evidence for active transport regulation of cerebrospinal fluid $\mathrm{pH}$ and its effect on the regulation of respiration (abstract). J. clin. Invest. 1963, 42, 977.

12. Held, D., V. Fencl, and J. R. Pappenheimer. Electrical potential of cerebrospinal fluid (abstract). Fed. Proc. 1963, 22, 332.

13. Merwarth, C. R., H. O. Sieker, and F. Manfredi. Acid-base relations between blood and cerebrospinal fluid in normal subjects and patients with respiratory insufficiency. New Engl. J. Med. 1961, 265, 310.

14. Robin, E. D. Abnormalities of acid-base regulation in chronic pulmonary disease, with special reference to hypercapnia and extracellular alkalosis. New Engl. J. Med. 1963, 268, 917. 